\title{
The Gift Economy and the Development of Sustainability
}

\author{
Thygesen, Niels
}

Document Version

Accepted author manuscript

Published in:

Local Economy

DOI:

10.1177/0269094219882261

Publication date:

2019

License

Unspecified

Citation for published version (APA):

Thygesen, N. (2019). The Gift Economy and the Development of Sustainability. Local Economy, 34(6), 493-509. https://doi.org/10.1177/0269094219882261

Link to publication in CBS Research Portal

\section{General rights}

Copyright and moral rights for the publications made accessible in the public portal are retained by the authors and/or other copyright owners and it is a condition of accessing publications that users recognise and abide by the legal requirements associated with these rights.

Take down policy

If you believe that this document breaches copyright please contact us (research.lib@cbs.dk) providing details, and we will remove access to the work immediately and investigate your claim. 


\section{The Gift Economy and the Development of Sustainability Niels Thygesen}

Journal article (Accepted manuscript*)

\section{Please cite this article as:}

Thygesen, N. (2019). The Gift Economy and the Development of Sustainability. Local Economy, 34(6), 493-509. https://doi.org/10.1177/0269094219882261

\section{DOl: https://doi.org/10.1177/0269094219882261}

Copyright (C) The Author(s) २०19. Reprinted by permission of SAGE Publications.

* This version of the article has been accepted for publication and undergone full peer review but has not been through the copyediting, typesetting, pagination and proofreading process, which may lead to differences between this version and the publisher's final version AKA Version of Record.

Uploaded to CBS Research Portal: August २०२० 


\section{The gift economy and the development of sustainability}

This article contends that a new perspective on the economy - a gift economy - would be beneficial to the development of sustainability. The principles and practices of the gift economy (giving, receiving and reciprocating) are exemplified by a case study of the Danish island of Sams $\phi$, which has used it to achieve environmental sustainability, improve its economic situation and generate social value. In order to illustrate the values and principles that underpin the gift economy, the article shows the underlying exchange mechanisms used in this modern version of 'gift-giving' and contrasts them to using money as the medium of exchange. One of the mainstays

of the gift economy is the willingness and obligation to reciprocate, and the case study highlights some of the original ways of organising that have emerged from the gift economy on Sams $\phi$ and how significantly they differ from organising and managing by budgets. As such, the article attempts to reframe the understanding of the economy and, in particular, to qualify and illustrate the potential of the organising principles behind the gift economy and encourage readers to conduct further research and engage in initiatives that will make a positive contribution to the development of sustainability.

\section{Background and idea behind the article}

The fact that the world needs collective efforts to promote sustainability has now been established beyond any shadow of a doubt. The United Nations Sustainable Development Goals (SDGs) serve as a blueprint for a better and more sustainable future for all. They address the global challenges, including the climate and the environment, that form the focus of this article. Although the projected trickle-down effects of the SDGs and other public-sector initiatives may be debatable, it is no longer a matter of whether sustainability is needed or not. The question is: How?

In the context of this article, the question of 'how' implies a distinction between sustainability on the one hand and the development of sustainability on the other. It takes sustainability to mean humanity's goal of human/ecosystem equilibrium (www.globalfootprints.org. Retrieved 201805-02). This generally accepted definition covers three dimensions: 1) a goal, which makes the future something to be addressed in the present (temporal dimension); 2) quantifiable environmental/ecological sustainability (object dimension); 3) social sustainability, which has to be experienced and enacted (social dimension). However, this focus on 'how' diverts the main focus away from the 'goal' to deal with processes that allow the future to be addressed in the present, i.e. the development of sustainability. This article extrapolates on the development of sustainability and illustrates the organising principles mediated by a gift economy and by which target goals are both meant to emerge and be achieved with reference to the Danish green Island of Samsø.

To date, the development of sustainability has mainly been conceptualised, managed and organised around a money economy. The World Economic Forum declares, for instance, that: 'The money is there to fight climate change' (https://www.weforum.org/agenda/2017/09/themoney-is-there-to-fight-climate-change/). Governmental initiatives, regulation and restrictions imposed on private companies are usually based on financial calculations, and implemented by 
means of economic and/or political sanctions (see Report by the Commission on the Measurement of Economic Performance and Social Progress) - in short, they are subject to management by budget. The key to this debate is how and to what extent each nation, local authority and public body - possibly along with other stakeholders and through partnerships will make (or can afford to make) the economic sacrifices needed, and to what extent sustainability will also generate (economic) benefit. Three questions are posed: What does social sustainability cost? What does environmental sustainability cost? What would be gained from investing in them? In order to quantify the benefit of investing, social and environmental sustainability are usually addressed separately, each with its own budget, administration and management.

This article takes the view that these three questions are the key to understanding institutional, organisational and economic choices, and that reactions to them reflect the priority accorded to answering them. What is striking is that the money economy is rarely treated as both the solution and the problem. To a large extent, the money economy has been seen as the overall solution because money - along with the management and organisational principles of budgeting and accounting - are considered effective and powerful means of developing initiatives and steering towards goals. However, this solution is also the problem in so far as it prevents the potential of other 'economies' from being exploited. To be precise on this matter, the article does not seek to critique the money economy, and the way that targets follow money and money follows targets. The problem is the one of perspective and thus blindness, that is, if developing sustainability is conceptually and practically excluded from the value provided by the organising principles of an alternative economy, a gift economy.

The concept of the gift economy emerged from anthropology and sociology and has been taken up by political science and economics, and an understanding of what defines acts of gifting seems to transcend the disciplines: the obligation to give, the obligation to receive and the obligation to reciprocate (Eisenstein, 2011; Putnam, 2000; Derrida, 1997; Bourdieu, 1979; Mauss, 1925). Based on this definition, the question is:

How can we recreate an understanding of economics that paves the way for organisational principles that will connect the often separate areas of social sustainability, i.e. social and environmental development?

This article's attempt to create a different understanding of economics and to show the potential of a gift economy is a theoretical endeavour, and the empirical data is meant to be illustrative. The article starts with an account of the meta-theoretical approach upon which the theoretical argument is based. It then extrapolates on the principles of the money economy and the gift economy in order to illustrate that a gift is another media of exchange that we can conceptualise, manage and organise our way toward greater sustainability. This is followed by an illustrative case study, in which the Danish island of Sams $\varnothing$ is presented to demonstrate how significant problems were avoided and remarkable results achieved by means of a gift economy. The conclusion at the end of the article will sum up the conceptual and practical implications of 'the gift' and point out the need for further research and practical experiments concerning the potential value of the gift economy. 
In some respects, the model is similar to the Local Exchange Trading Schemes (LETS) in several countries in the 1990s. Indeed, readers of Local Economy will be familiar with the concept of developing alternative economic models or strategies from the UK in the 1980s, when they were devised to counter the dominant neoliberal approach adopted by the Margaret Thatcher and her Conservative government. The LETS approach in the UK and its place within a broader alternative economic strategy to that of the Conservatives was also part of a much wider debate about the role of local government at a strategic level in supporting alternative social and economic approaches at a local level. It is this part of the LETS legacy, which is important in this context. This article, and the others in this edition of Local Economy, seek to establish links between the needs of local authorities and/or communities and alternative ways of conceptualising economic policy.

\section{Meta-theoretical approach}

Within the context of this article, the way in which the analytical separation and comparison between a money economy and a gift economy are presented rests on the distinction between media and form offered by Luhmann (2012). Luhmann's concept of media parallels to some extent the concepts of technology in Science Technology Studies (STS) and Actor Network Theory (ANT), which is considered a medium, and thus an actor that mediates processes between persons, materials, signs and symbols. One of those is money. However, there are also differences. According to Luhmann, a media mediates, but it does so by endowing processes with specific forms. For instance, money is a medium that gives form to transactions. Based on his concept of media, Luhmann considers the commonly accepted and generalised media, for example, money, specific to the recursivity of systems (Luhmann, 1995), that is, the way the whole economy operates.

There are many layers of theorising related to the distinction between media and form, among others programs in terms of budgets, accounts and calculations, and by which societies and organizations structures their own transaction processes. Although important, programs only require a brief note for the argument of the paper.

The first advantage of the distinction between media and form is separation. Despite the obvious fact that a gift can be bought (for money) and money can be given away (as a gift) it is not uncommon for sociologists and anthropologists either to make understandings of economy more social, i.e. embedded in society and culture (Polányi, 1944; Block, 2003; Laville, J-L, 2014) or even to distinguish money economies from other social economies and point out how they differ in value (Eisenstein, 2011; Putnam, 1995; Fukuyama (1995). What all of this work has in common, however, is often the definition of money and other economic symbols as media of exchange. This is especially evident in socio-economics because it has the advantage that exchanges mediated by money, much in line with Luhmann, can be observed as specific interaction and communication processes and, even more commonly, as the structuration and reproduction processes of societies, communities, classes, tribes etc. (Gan $\beta$ mann, 1988). To sum up, in the context of the article, the advantage of separation is that money and gifts are two media that give form to different economic processes. 
The second advantage of the distinction between media and form is that it facilitates comparison. A medium that gives form to processes (money) can be compared to another medium that gives form to other processes (gifts) on the same level of abstraction because they share the same function -mediating economic processes - but differ in form. They are, as Luhmann notes, functionally equivalent media, as they are both economic and as such comparable. Again, to sum up in the context of this article, the advantage of comparison is not only the ability to contrast 'money' and 'gifts' as two distinct economies, but also the possibility of developing the potential of the latter in order to provide new ways to conceptualise, innovate in and enhance sustainability.

As well as these advantages, this meta-theoretical approach also has its limitations. Although it is beyond the aim and scope of the article to engage in a full theoretical discussion on this issue, two aspects are worth mentioning because they also show the limitations of the article. On a theoretical level, this approach does not allow for examinations, illustrations and empirical studies of grey zones, nor for the intertwinement of different economic processes. Clearly, approaches relying on network ontologies such as STS and ANT would compensate for this blind spot. On an empirical level, this approach is demanding due to the level of abstraction.

The form offered by a media is highly generalised and would benefit from more than initial examinations and illustrations to be completed, that is, from a large archive in order to observe the programs of economic exchange and in-deep empirical work in order to gain knowledge of the intimate processes.

The form offered by a medium is highly generalised and would benefit from more than initial examinations and illustrations. An extensive archive would be preferable, in order to observe the programmes of economic exchange, combined with in-depth empirical work to generate knowledge of the intimate processes.

\section{The economic principles}

This section will compare the gift economy to the money economy on the basis of four principal dimensions in order to show how the former provides an alternative to the latter. The first two dimensions are the medium and the form of exchange. The third dimension is the principal value, which is divided into two subsections: hard value and social value.

In distinguishing the gift economy - and in particular emphasising the concepts of hard value (value measured objectively) and social value (the experienced value of being related) - the article draws on various anthropologists and sociologists. It draws on Mauss (1925), Bourdieu (1979) and Derrida (1997) and their understanding of gifting and on the empirical-critical research into societies by Putnam (1995; 2000; 2004) and Fukuyama (1995), which looks at the mechanisms of gifting in order to identify the values associated with it in terms of community building, social capital and measurable economic facts. It also draws on Graeber (2013) and Eisenstein (2011) as the latter specifically treated gifting as a separate economy that can be compared with a money economy. What unites this area of research is the interest in the way by which economic exchanges are mediated and how 'economy' also is to be conceptualised in 
terms of other medias than money. Putnam, Fukuyama, Graeber and Eisenstein all also attempt to analyse and discuss (the loss of) public value if overdetermined by a money economy. In particular, they are concerned with both hard economic facts (hard value) and the experienced value of communities (social value). It is, in their view, the combination of both of these values that constitutes public value.

In this article, the combination of both values demonstrates the potential of a gift economy but more specifically in regard to sustainability. However, in an attempt not to neglect the fact that the proof of the pudding is in the eating, the value of a gift economy is illustrated by the case study of the Danish island of Sams $\varnothing$ and the organisational principles that have attracted worldwide attention.

\section{Hard value - moving beyond zero-sum}

A money economy is mediated by money, and financial transactions include goods, labour and knowledge. Zero-sum logic has been used to demonstrate the limits of a transaction-based economy (Thurow, 1986). For example, a lawnmower with a retail price of $€ 1,000$ is bought for that sum, and the economic transaction is characterised by the mower and $€ 1,000$ swapping places. In this financial transaction, which is based on choice, there is no added value on either side other than the probability that the seller favours/needs the money and the buyer favours/needs the lawnmower. This is the hard value. However, the choice of transaction also implies subjective value, consumer value (Acemoglu, Laibson \& List, 2016). This value rests on the difference between how much the amount that the first party is willing to pay exceeds the price of the item. As such, zero-sum is not zero value. Zero-sum includes the value of owning the lawnmower plus the consumer value. Having said that, value has been termed 'zero-sum' in at least three ways (Acemoglu, Laibson \& List, 2016). The first refers to the idea of a markedequilibrium as price and willingness to pay adjust to each other. The second refers to the idea of marked competition as one party's additional gain is the other's loss. The third refers to game theory and introduces social strategies based on expectations of possible gains and losses.

A gift economy is mediated by gifts. Like a money economy exchanges include goods, labour and knowledge (Mauss, 1925). However, the gift is an alternative medium, and as such, it gives form to different economic exchanges than financial transactions. These exchanges have been described in terms of 'plus-sum', i.e. potentially offering added value to both parties. One party might own a lawnmower, another a hedge trimmer. One party offers the other access to her mower as a gift, and the other offers access to his trimmer as a return gift. Both parties still own a garden tool, but they are converting ownership and consumer surplus into a gift economy by sharing them. In other words, one party can enjoy the value of a mover and a trimmer and the other party can enjoy the value of a mover and a trimmer. The principle plus sum value in this example means that one mower plus one trimmer equals the value of two mowers plus two trimmers.

Money was, of course, involved in the initial purchase of both garden tools. The point is, therefore, not about separation but about conversion. The money economy is neither separated 
from a gift economy, nor does it vanish when gifting is introduced. However, it is converted into a gift economy when both parties provide access. No money is then involved, only gifts.

Banks and investors trigger transaction costs, which add negative value to the 'zero' in zero-sum because the expense of third-party monitoring is often considerable. However, in a gift economy, transaction costs are minimised as the expense of contracts, monitoring and control by third parties is reduced, if not replaced by social obligations which may even develop into norms of reciprocity. This was one of the significant points made by the economist and Nobel prize winner, Oliver Williamson, who introduced trust between parties as an equivalent and substitute to the (expense) of contracts in markets. It was the point made in Fukuyama's analysis of prosperous countries based on norms of reciprocity and by Putnam, who regretted the decline of social capital in the United States.

This exchange based in gifting, as Derrida and several anthropologists noted, is a logical paradox: as a gift is a non-gift in order to be a gift (Derrida, 1997). On the one hand, a gift is only a gift if it is given without any expectation of receiving a gift in return. If a return gift is expected, then it is a transaction. Yet, on the other hand, a gift implies an obligation not only to receive but also to reciprocate. If not, then the recipient is considered a free rider and will potentially be excluded from the economy. As such, gifting differs from the straightforward nature of financial transactions and takes social-contextual skills.

While Derrida extrapolates on this paradox, Bourdieu conducted empirical studies of how the paradox is dealt with in terms of time lags (Bourdieu, 1996). As mentioned above, a gift followed immediately by a return gift, it is observed as a transaction, and if a gift is not followed by a return gift, it is observed as free riding. However, if the gift is followed by the right time lag, then it is observed as a gift but also facilitates a return gift. In other words, gift-giving involves social-contextual skills and socio-temporal competencies.

\section{Hard value as open access}

Obviously, a gift economy represents a sustainable solution because there is no longer any need to buy another trimmer or mower. It is not an investment by me. It is an investment in us, in 'access' as opposed to 'ownership'. On a much larger scale, the gift economy paves the way for sustainable solutions in the exchange of land, technologies, waste, ideas etc. provided they are based on greater access, a potential exemplified by the success in agriculture, food, transportation and energy on the Danish island of Sams $\emptyset$. As the case study also illustrates, creating a gift economy is a matter of being willing and able to conduct experiments with assemblages of things, materials, places and people. In other words, the organisational principles are based to a larger extent on trust (in terms of risk-running as opposed to planning) and on emerging targets and multiplying value as opposed to set targets and value calculated in advance.

When establishing a gift economy as a means to sustainable solutions, it is worth remembering that the concept of plus-sum has also been associated with the knowledge economy (Kodama and Branscomb, 1995; Jie, 2011), which means that it also covers experiments with ideas, 
knowledge, innovations etc. and, as the case study shows, is deeply intertwined yet thoroughly organised with things, materials, places and people.

\section{Hard value multiplied}

So far in this article, the examples have featured two parties. However, gifts are more inclusive than money as they substitute money (a singular entity) with gifts (multiple entities) and while the former is a scare resource, there is no limit on the latter. A gift can be an idea, a favour, a tool, a technology, expertise, knowledge, contacts or access to other networks. For instance, the two parties exchanging tools most likely have children and a third party might become part of the gift economy as by taking the children to school every morning. This might be an obvious thing to do if he works near the school. "How nice. What a great idea!" might be the response from the owners of the tools, and after talking it over, they might decide to mow his lawn and trim his hedge whenever necessary. Not only does this expansion of the gift economy save time and money, but it also saves on petrol and emissions as the need for cars every morning is cut by two-thirds. With the inclusion of the third party, the principal value has multiplied again, as each party now has access to three goods If a fourth party then joins the 'economy', then four equals 16 and so forth. The value multiplies, and, in principle, exceeds the consumer value by far.

As already discussed, these principles are highly extrapolated and generalized. Grey areas appear, for instance, when three parties pool their money, so one of them is able to make a larger investment every third year. This is a gift economy, albeit based on money, and might be found in families and small communities. However, on a larger scale, this circularity has been converted into a money economy, with banks performing the same function of pooling resources, only now based on debts, interest rates and contracts as opposed to social obligations and norms of reciprocity. Banks convert a gift economy into money. This also to stress, that in so far as sustainability initiatives are based strictly on money, then it might endanger a gift economy and even bring individuals, organisations or nations into debt relations or furious competition. Sustainability might become a mean to own economic success rather than an end in itself.

\section{Hard value as generative and form-shifting}

A gift economy does not just have the potential to multiply hard value. It is also potentially generative and form shifting. When people share resources, driven by the idea of a value that is not yet articulated, it is seen as building the social desire to add or give something, to contribute to the pool of resources or networks of exchanges, and each new contribution has the potential to develop or change the form of the gift-giving. While Williamson's argument was mainly about reducing transactions cost, one of the significant arguments advanced by Putnam on the basis of his empirical work was the ability to generate new forms. Social capital, which is the (return-) capital that you build by giving, is not specified by a formal contract. A network-based on gifting might only deal with gardening at first but transform into a green network, saving fuel and reducing emissions when a third party joins in. By comparison, a money economy based on zerosum logic is driven by individual desires, individual ownership and expected consumer surplus, 
all of which are guaranteed by contracts that specify the (conditions for the) transaction and in doing so preserve the form and the exchange and preclude generative or form-shifting processes.

\section{Social value as community}

There is no doubt that the effectiveness of a money economy is based on self-interest and nonsocial relations, and the transaction only a fleeting one as the exchange takes place. No further social obligations are required. Nor is there any need to know about each other before or after the transaction. In fact, the effectiveness of the transaction depends on not trying to get to know each other, as any social interaction will slow down the transaction and, on a larger scale, the whole economy. The money economy has become an all-inclusive economy and expanded across time and space not despite the fact that the transaction is a non-social relation but because of it.

A gift economy relies to some extent on being present but always relies on reciprocity, which is continued and guaranteed by the social obligation to reciprocate. In other words, it is a social economy and by its ability to include, expand, and generate, it builds and is built on community - in local forms (close relations based on simultaneous presence or in digital forms (distant relations based on displaced presence and as bonding (confidence) or bridging (trust). This brings us to the social value of the gift economy as social relations not only create value; they are valueable. Social relations, based on social obligations and by desires to create and 'become than one' is not only a human deed but also a human need.

Being a community that generates value is a value per se because it offers purpose (why are we together), identity (who are we), and prosperity (what do we create together). Social (and sustainable) ties, then, does not exist outside the economy. It is within economy. Gift economy is, in other ways than the money economy, able to grasp and generate the potential value between people, things and places.

As noted by Eisenstein, the significance of social value becomes evident when digging into history. The meaning of community originates from communion, the Christian act of breaking bread together. It is an act of obligation(helping those in need) and it an act of reciprocity (the recipients are obliged to share whenever they are able). There is no contract, no ownership, no self-interest and no consumer surplus. Gift giving is a practice so fundamental to human beings, that it has become part of religion, which elevates it into a principle and need higher than individual, organisational or national (self-)interests. For the same reason, Eisenstein complains that the economy is no longer sacred, Fukuyama criticises ideologies and institutions that only favour and stimulate a money economy, and Putnam complains that we are now bowling alone. They express these regrets not for moral reasons or religious beliefs but because of the tremendous social value of a gift economy is squeezed out, leaving individuals, professions, organisations and nations not only poor but also lonely.

The point being made here is that we are more than separate and isolated individuals, places and materials and that sustainable relations, or social sustainability, are not outside of the economy. They are the economy, but it is not one mediated by money. 


\section{Economic exchange and the two values}

So far, the principles of the two economies have been compared on the basis of two value dimensions, hard value and social value. Hard value is the value created by the economic exchange. Social value is the value of the exchange relation.

- The money economy only operates with a hard value generated by the exchange and this is, by definition, not a social value. The hard value of the transaction is a 'zero-sum' value consisting of ownership and consumer surplus.

- The gift economy operates with hard value and social value generated by the exchange. On the one hand 'plus-sum' has multiplying and generative effects (hard value) and on the other hand, it is based on and creates 'community' (social value) due to social obligations and the desire to create.

Clearly, the two types of economies are different value programmes. Taking into account the fact that the development of sustainability has mainly been conceptualised, managed and organised around a money economy, the value of the gift economy remains unexplored. It is not only different from the value created by financial transactions; it also creates hard value and social value within the same exchange. Gifts bridge what money separates - hard value and social value. Gifts rest and build on what financial transactions in principle break up - community.

\section{The two types of economy summarised}

In short, this article has extrapolated on the principles that underpin the two different types of economy in order to show the potential for hard and social value in a gift economy and how to generate both at the 3 same time. The two economies are summarised in the table below:

\begin{tabular}{|c|c|c|}
\hline & Money economy & Gift economy \\
\hline Medium & Money & Gift \\
\hline Form of exchange & Transaction & Reciprocity \\
\hline Hard value & \begin{aligned} & \multicolumn{2}{l}{ Zero sum } \\
&- Ownership \\
&- Specified value \\
&- Form preserving \end{aligned} & $\begin{aligned} & \text { Plus-sum } \\
&- \text { Open access } \\
&- \text { Multiplied value } \\
&- \text { Generative and form } \\
& \text { shifting }\end{aligned}$ \\
\hline Social value & None: Self-interest(s) & $\begin{array}{l}\text { Community: Social obligations } \\
\text { based on reciprocal } \\
\text { arrangements }\end{array}$ \\
\hline Hard value \& social value & Separated & Integrated \\
\hline
\end{tabular}

The table distinguishes between the exchange principles of a money economy (middle) and a gift economy (right). The column on the left divides the principles into the four concepts by which the two economies are compared: media, form of exchange, hard value and social value. 
Having established the principle differences between the exchange mechanisms of the two economies, the article will now proceed to the case study, presenting the official, documented results achieved by the Danish island of Sams $\varnothing$, followed by three initiatives that represent different ways of organising based on a gift economy. Finally, the case in terms of the three initiatives are summarised.

\section{Samsø}

Sams $\varnothing$ is a community where the islanders, volunteers, local craftsmen, companies and, in particular, dedicated officials and staff of the local authority have worked together to turn the island into a green one. In 1997, Samsø was named a 'sustainable energy island'. This entailed drawing up a budget and plan that would convert from fossil fuels to renewable energy. By 2018, the official Sams $\varnothing$ website[1] stated that:

- In 1997, Sams $\varnothing$ was named a sustainable energy island, and a decade later it was selfsufficient in renewable/sustainable energy.

- By 2007, 100\% of all energy used on the island was generated by 11 land-based windmills, and renewables fuelled $70 \%$ of all heating.

- More than half of the oil-burning heating systems in the 2,000 homes have been replaced by privately-owned sustainable energy sources such as solar panels, pellet burners and heating pumps connected to the central district heating plant

- 10 sea-based windmills produce a surplus of energy, which fully compensates for the heating coming from the remaining oil-burners. As such, the whole island is not only $100 \%$ self-sufficient in renewable energy; it also exports energy to the rest of Denmark.

Initially, the local authority was supposed to draw up the budget and plan for the transition. But it turned out that neither money transactions should mediate the processes of developing sustainability nor should the local council be the sole authority. Not enough money to make the island sustainable accompanied the title, so the main challenge was at first was not a question of energy but economics.

As a result, instead of the council launching a planned process, the process came before the plan. On the Island of Sams $\varnothing$, this turned out to be a reversal of management. Instead of starting at the apex of the hierarchy, the process started with social visits and learning about the community; instead of being a sequentially planned process it multiplied due to a chain reaction of initiatives; and instead of making the most of scarce resources, money was spent on mobilising the islanders and later on an Energy Academy with its own management, which essentially mediates the conversion processes on Sams $\emptyset$.

Today, the island is sustainable in terms of institutions (the Academy), socially sustainable (the community has been mobilised) and sustainable in terms of energy (100\% self-sufficient in renewable energy). It all started, however, with a social visit that triggered processes of gifting. 
The blacksmith: seeing the value of gift-giving.

In 2002, the official in charge of the energy plan called on the local blacksmith in Norby. The manager had failed horribly when attempting to explain the planned (budget behind the) district heating plant to the islanders at a public meeting. After this disappointment, the manager changed his worldview. Rather than view the islanders as obstacles to the plan, he viewed the plan as an obstacle to active citizenship. He approached the blacksmith because he was the unofficial mayor of the island. Committed and well-spoken, he was also the person households turned to on cold nights when their oil burners broke down. He was, of course, against green energy and the planned district heating plant. Not only had some district heating plants elsewhere in Denmark cost households money, but he would also lose business if the number of oil burners was reduced. The official convinced the blacksmith that his business might prosper if he involved himself in the plumbing and technical supervision needed by households, local farmers, businesses and public institutions. He could also see the advantage of other islanders gaining an advantage - if they prospered, he would prosper and vice versa. Servicing a district heating plant would demand new skills, but he was willing to take on the challenge. The blacksmith promised to show up at the next public meeting if it took the form of a process - a hearing involving all relevant stakeholders and not the other informal 'mayors' on the island.

The blacksmith, the 'mayors', the local authority official, companies and many of the islanders turned up and were the first to be thrilled to be part of a community driven by a common purpose (social value) and with a value potential for the whole island (hard value). In a theoretical sense, they moved from a zero-sum situation - where individual value was based on the self-interest of each citizen, each business and each local administration - to a plus-sum situation, driven by common interests and social obligations and desires. They prioritised a different type of economy, a gift economy.

\section{Active citizenship: Giving, receiving and reciprocating}

The first achievement on Samsø was, therefore, the district heating plant. Note that it was not the deliberate outcome of a plan and budget. It was the result of involvement, which went much further than just conveying legitimacy on a plan after a public consultation. The blacksmith and other local businesses were now involved in the construction of the plant, which not only gave form to the plant and a source of income to local companies but also new knowledge of the whole energy system. A gift-circle had begun. Hard value was based on future needs for plumbing, repairs and parts which local craftsmen and companies were now capable of supplying. They had become experts in green energy and reliable suppliers of skills, knowledge and parts. Within this network, it 'paid' to help and supervise each other (even competing companies) as the gains outstripped any potential losses and also meant that there was less need to ferry in help from elsewhere at peak periods. Helping others was helping themselves.

According to a cost-benefit analysis based on money, a small amount could have been saved by using outside experts. This was the initial plan and budget. However, the savings would also have detracted from the benefits of a mobilised community and of prosperous local craftsmen and companies on the island. According to the logic of a money economy, the return of 
investment would be evaluated in financial terms. However, in this case, the investment was in arranging processes that encouraged active citizenship and involved and trained local craftsmen and companies. Although he did not distinguish between a money economy and a gift economy, the value of gift-giving was the initial point made by the blacksmith and taken up by the official from the council. And even more important, this was the narrative emerging on the island, and which distributed a sense of community cutting across old rivalries.

\section{The windmills on land: Being more than one}

The success of the central heating plant and widespread interest in the issue of sustainability led to the next step: building windmills on land and at sea. The council official now knew how to organise the process and involved the stakeholders and wider community not just for reasons of legitimacy but to promote exchanges based on gift-giving and plus-sum. Although many calculations were made, the windmills were neither based solely on a cost-benefit analysis nor dependent on private investors and venture capital. They were $90 \%$ financed by share issues to the islanders. This level of commitment came as a surprise to the council official, but the formal community that had arisen around sustainability (the craftsmen and companies involved) and the informal one (supporters of green energy initiatives) was confident in the ability of the central distribution plant. In other words, the confidence in gifting now became future directed and twofold: It became too obvious for the craftsmen, the businesses and the supporters, that giving a share meant receiving (the benefits and the community provided by) a windmill. And a desire among participants to experience what can emerge if we are engaged in sharing and the common good was awakened.

The collective commitment and desire to participate went further than just a willingness to run the risk of co-ownership. Islanders now did many of the expensive tasks. For example, if a landbased windmill stopped due to a change in wind or weather conditions and manual or digital changes were needed, the nearest neighbours agreed to take charge rather than wait for a technician to be shipped in. There were two reasons for this: it was in their own interest as coowners of the windmill, but even more importantly the majority of their fellow islanders also owned shares, which made them feel a greater obligation and motivation to take on such roles. This allocation of responsibilities kicked in when the windmills started running in 2007 and the number of breakdowns on Sams $\varnothing$ is now lower than the average elsewhere.

From an economic perspective, the gift economy in this instance takes the form of social shareholding and covers both hard value and social value. The hard value became evident when a majority of the islanders chose to buy one or more shares. As such, each of them converted ownership (what is mine) into a gift economy (what is ours). The reciprocity of gift-giving is epitomised by the fact that the shares are not in specialised parts of the windmill, like a wing or a cogwheel. They are collective 'shares'- what is mine is yours, and what is yours is mine. The value in terms of plus-sum is that giving a small part (a share) benefits the whole unit (everybody benefits from the windmill), and taking care of the windmill means everybody benefits from fewer breakdowns. The social value emerged from social obligations, i.e. the fact that neighbours took on these responsibilities, something acknowledged in their narratives and shown by the huge social capital among the rest of the islanders which they are eager to pay back by way of 
other gifts. Today, the windmills' neighbours are acknowledged at the annual sustainability festival (sponsored by a local company) at which stories of 'saving the mills' are narrated, retold and spread.

\section{From sustainability to sustainabilising}

The most compelling example of shareholding and co-ownership on Sams $\varnothing$ is definitely the landbased windmills. However, when the Energy Academy was built in 2007, the same type of gift economy emerged again, albeit on a smaller scale. Part of it was built by local craftsmen, local companies provided some of the materials, and a considerable proportion of the manual labour was by volunteers. The craftsmen and companies were paid, of course, but the costs were greatly reduced, and the process speeded up immensely due to the shares and the interest everybody had in the project. The Academy is not co-owned like the windmill, but it is based on co-interests, and it serves as well as creates co-interests in sustainability. In other words, sustainability has turned into processes of sustainabilising. Today, the Academy is a sustainability icon in terms of mobilised projects and outputs. The hard facts might sound more convincing than the social value of bonding and bridging, but the latter has become more and more crucial over time. One example is the seminars, hosted by the academy and which has not only has generated and multiplied value by which sustainability has developed.

\section{The seminars: open spaces lighting the social fire and desire}

The Energy Academy operates as a formal hub for professionals as well as an informal one for the community. Due to its multiple functions, it has multiple unofficial names: a public hall, a demonstration site, a project house, exhibition hall but never a 'department' or 'administration'. It runs seminars on 'best practice' and 'next practice' that attract approx. 5,000 researchers, companies, politicians, journalists, students, young people and tourists from most of the world per annum. The most formal seminars are the ones for researchers, politicians and companies while journalists, tourists, students and young people attend on a more informal, day-to-day basis. 'Best practice' and 'next practice' concentrate on two issues: the hard facts about sustainability and its practices, in other words, what of kind of social initiatives, informal processes and organised practices have led to the remarkable achievement of being the first island in the world to be self-sustainable in green energy. This is also why the research seminars and seminars on partnerships attract scholars involved in organisational and management studies as well as the humanities. Equally importantly, they are attracting scholars and managers interested in economics because the island is considered difficult to explain by means of orthodox theories. Being considered an 'economic phenomenon' has even been turned into a joke and an anecdote (it is called the bumblebee because it defied gravity until its laws were changed).

The gift economy here does not take the form of shares but relies more on the development of knowledge. Ideas are exchanged and developed by scholars, experts and practitioners from the island as well as private companies, entrepreneurs and politicians. The value principle of 
exchange, and especially the exchange of knowledge, is somewhat different from the value of sharing a windmill. The principle is quite familiar in academic and entrepreneurial circles as the reciprocity involved in sharing an idea results in both parties comping up with more new ones. Whenever a third party enters the exchange process, the value increases. This is why the Academy is pleased to host the seminars despite all the hard work involved. There no doubt either that the thousands of researchers, politicians and professionals from private, public and voluntary organisations are pleased to attend. Nor is there any doubt that a majority of this community, based on the new friendships and loose ties they forge at the seminars, are enthused to learn from and be part of the 'economic bumblebee'. Everybody involved gets smarter, and so does the island. The bumblebee is also fuelled by a new goal discussed and developed at the seminars: to be the first fossil-free island in the world by 2030 .

It may sound as if the gift economy excludes children but having visits from kindergartens had been of great value and are accorded high priority. The curiosity of the kids from Rumlepotten (the name of the kindergarten) resulted in a screen in their playroom, which now shows the amount of energy saved by the solar cells on its roof. The children are now aware of 'energy', local entrepreneurs and designers have all been involved in the process of making energy visible in a way that is intuitive and slightly dramatic, and researchers have been able to study how children learn about issues that are difficult to demonstrate to them.

\section{The ferry, the land and nature: Gift-giving as on-going and form-shifting processes}

A notable project has emerged from the seminars. Sams $\varnothing$ aims to be a (role)model for a green environmental circuit based on waste. The 'Bio-island Sams $\emptyset$ ' project is now in full swing. The idea is to re-conceptualise waste as forms of energy and fertilisers. The project is centred around a new biogas plant completed in 2018. The plant transforms waste, such as leftovers, sewage, plant residue and slurry, into green energy in the form of biogas used, among other things, to fuel the ferry, Princess Isabella, between the island and Jutland. The key is that the waste stems from fields and bins on the island, so that is part of a circuit and has a direct effect on the island. Not only is the ferry fuelled by biogas, but it has also become the symbol of a minor agricultural revolution and a change in waste culture. One side-effect of the biogas production is that any excess waste that the plant cannot transform into biogas is returned to the fields as fertiliser. All this is happening at the same time as the local farmers are slowly converting to sustainable crop production and free-range hens, sheep, pigs and cows.

The islanders now talk about a 'circuit revolution' as opposed to a linear economy and about different circuits. From the perspective of a gift economy, there are two circuits associated with Bio-island Sams $\emptyset^{\prime}$ and symbolised by the ferry. The first is the one of which waste is either converted into clean energy or returned to the fields as fertiliser. The second is one by which the value to the individual citizen consists of saving energy and saving nature. What emerges clean from nature is returned clean to nature again. In both cases, the gift economy takes the form of input and output but not in a linear way. In the circuit, output (waste from the fields) becomes input (to the biogas plant) and which becomes input again (fuelling the ferry). Or, in more metaphorical but tangible terms, the gift is the output from one party that is valuable to the other party as input, and so on. 
Other projects are now slowly starting to emerge from 'Bio-island Sams $\varnothing$ '. One of them seeks to find the perfect combination of crops to preserve nitrates and fuel the biogas plant as efficiently as possible. Another involves the golf-course. The grass collected by the lawnmowers is to be delivered to the biogas plant which will convert it into grass and return the excess to the golf course as fertiliser. A third project has general health implications as it is looking into the idea that cabbage waste may contain substances capable of counteracting cancer of the intestines. The circle are not only expanding, but they are also form-shifting processes and are due, not least, to the seminars.

Summarising the case study

The table below summarises the case study - the Energy Academy on the Danish island of Sams $\varnothing$ - and shows how it has become a hub mediating different activities on sustainability.

\begin{tabular}{|c|c|c|c|}
\hline & $\begin{array}{l}\text { The windmills } \\
\text { Shareholding } \\
\text { Economy }\end{array}$ & $\begin{array}{l}\text { The seminars } \\
\text { Exchange Economy }\end{array}$ & $\begin{array}{c}\text { The Ferry } \\
\text { Circular Economy }\end{array}$ \\
\hline Medium & Gift as ownership & Gift as knowledge & Gifts as waste \\
\hline Form of exchange & $\begin{array}{c}\text { Part/unit } \\
\text { My part becomes a } \\
\text { share in our unit }\end{array}$ & $\begin{array}{l}\text { Mine/yours } \\
\text { My knowledge is } \\
\text { your knowledge }\end{array}$ & $\begin{array}{c}\text { Input/output } \\
\text { My output becomes } \\
\text { your input }\end{array}$ \\
\hline Hard value & $\begin{array}{l}\text { 100\% self-sufficient in } \\
\text { energy from local } \\
\text { windmills and other } \\
\text { technologies }\end{array}$ & $\begin{array}{c}\text { To generate 'best } \\
\text { sustainable practice' } \\
\text { and 'next sustainable } \\
\text { practice' }\end{array}$ & $\begin{array}{l}\text { The Ferry running on } \\
100 \% \text { bio-waste from } \\
\text { the local biogas plant }\end{array}$ \\
\hline Social value & Co-ownership & Interactions & $\begin{array}{c}\text { Common awareness } \\
\text { of nature }\end{array}$ \\
\hline
\end{tabular}

The three initiatives are listed in chronological order. The first major initiative on sustainability was a technological one based on co-ownership, which results in building eleven land-based windmills. The second was a purely collaborative initiative, the seminars. The third is a combination of both as 'Bio-island Sams $\phi$ ' seeks to combine technological innovation with an even stronger sense of collaboration and community. All three illustrate the gift economy: gifts as sharing, gifts as exchanges and gifts as circularity.

The column on the left repeats the four concepts in the conceptual strategy and, therefore, the way in which a gift economy is observed: First, the concept of media shows what becomes of a gift in the three cases. Second, the concept of the form of exchange shows how gifts are 
exchanged. Third, the concept of hard value shows the enhanced measures of sustainability. Fourth, the concept of social value shows how sustainability emerged as a particular variation of being a community.

\section{Conclusion}

This paper has argued that the development of sustainability can benefit from a new perspective on economy, a gift economy and with a special emphasis on qualifying and illustrating the value potential of the organising principles mediated by this economy

In particular, the article has presented some significant concepts that scholars, managers and even politicians can use to develop and study (the management of) new organising principles. More specifically, these concepts were used to consider the differences between gifts and money as the medium of exchange, as exemplified by the visit to the blacksmith, the windmills, seminars and ferry on the Danish island of Samsø.

Rather than drawing conclusions or presenting guarantees, the article is designed to provoke thought because, up until now, the development of sustainability has mostly been conceptualised, managed and organised around a money economy. As a result, sustainability - as taught in business schools, developed by scholars, refined by consultants and practised by managers - has often rested on the assumptions of a money economy. However, the case study showed that management by budget failed on Sams $\varnothing$ and the development of sustainability was mediated mainly by the exchange mechanisms of gifting (plus-sum and community) as opposed to money (zero-sum and self-interests). After all, the blacksmith might be right?

The article is also designed to provoke critical research into the arguments stressing the obvious benefits of a gift economy, in particular, the four concepts presented (media, form, hard value and social value) because they have limits. These limitations could be compensated for by the much broader concept of agency offered by the practice turn in management (Jarzabkowski and Spee, 2009; Golsorkhi et al., 2010; Vaara and Whittington, 2012; Seidl and Whittington, 2014) and by STS and ANT approaches in general, both of which would demand a 'follow-the-actors' approach or would at least follow an in-depth empirical and investigative research agenda. Studies of this type would not only provide tangible knowledge of the processes mediated by a gift economy and the specific value achieved, but they would also show the potential disadvantages, and even pitfalls, of a gift economy. For instance, the social obligations and reciprocal arrangements might have adverse and even spiralling effects, leaving 'no way out' from social ties or leading to the exclusion of those incapable of making a contribution or devoid of the social skills so profoundly associated with the exchange of gifts.

From a broader perspective, political science perspectives could also be applied to the potential disadvantages of a gift economy. Much emphasis has been placed on the positive effects due to the huge potential of a gift economy and the many case studies highlighting this potential. However, it is worth considering how and to what extent a gift economy, and other forms of social economies, would also undermine the regulating, organising and managing principles of society? How can politicians exercise democratic control and regulate a 'flat' society with rather 
informal ways of organising and creating value? What should we, the people, be aware of, when committing to reciprocal arrangements in society and our local communities?

That said, the article is one small step, a beginning, toward a grander task. In fact, the very distinction drawn between the gift economy and the money economy represents the article's blind spot. While this distinction proves fruitful in regard to simplifying, distinguishing and promoting the principal value of a gift economy and of illustrating new forms of organizing and managing, then the role of money as a basis for gifts remains out of sight, just as the grey areas and intertwining between both, cannot be investigated by such a particular distinction.

The point of suggesting critical research is not to undermine the gift economy. Rather, it is to encourage fellow scholars to apply critical attention to its study and development. As such, the article reflects a genuine hope that it will be possible to motivate research and initiatives that will make a difference to the development of sustainability. As stated at the start, the question is not whether sustainability is needed or not. The question is how?

\section{Bibliography}

Acemoglu, D., Laibson, D., \& John, A. List, 2016. Economics.

Block, F. (2003). Karl Polanyi and the writing of the Great Transformation. Theory and society, 32(3), 275-306.

Bounfour, A., \& Edvinsson, L. (2012). Intellectual capital for communities. Routledge.

Bourdieu, P. (1979). Symbolic power. Critique of anthropology, 4(13-14), 77-85.

Bourdieu, P. (1989). Social space and symbolic power. Sociological theory, 7(1), 14-25.

Bourdieu, P. (1996). The work of time. The Gift: an interdisciplinary perspective, 135-47.

Bourdieu, P. (2011). The forms of capital.(1986). Cultural theory: An anthology, 1, 81-93.

Derrida, J. (1997). The time of the king. The logic of the gift: Toward an ethic of generosity, 121-47.

Eisenstein, C. (2011). Sacred economics: Money, gift, and society in the age of transition. North Atlantic Books.

Fukuyama, F. (1995). Trust: The social virtues and the creation of prosperity (No. D10 $301 \mathrm{c}$. 1/c. 2). Free Press Paperbacks.

Ganßmann, H. (1988). Money — a symbolically generalized medium of communication? On the concept of money in recent sociology. Economy and Society, 17(3), 285-316.

Golsorkhi D, Rouleau L, Seidl D, et al. (2010) Cambridge Handbook of Strategy as Practice. Cambridge, MA: Cambridge University Press. 
Graeber, D. (2013). It is value that brings universes into being. HAU: Journal of ethnographic Theory, 3(2), 219-243.

Jarzabkowski P and Spee AP (2009) Strategy-as-practice: a review and future directions for the field. International Journal of Management Reviews 11(1): 69-95.

Jie, M. (2011). The Plus-sum Relations between Capital and Labor in the Creation of Value: A New Marxian Explanation Based on the Proportional Theory of Value Creation [J]. Economic Research Journal, 4, 003.

Kodama, F., \& Branscomb, L. M. (1995). Emerging patterns of innovation: sources of Japan's technological edge (Vol. 8, pp. 147-184). Boston: Harvard Business School Press.

Laville, J-L (2014). The social and solidarity economy: A theoretical and plural framework. In Jacques Defourny, Lars Hulgård and Victor Pestoff: Social Enterprise and the third sector changing European landscapes in a comparative perspective. London and New York:

Routledge.

Luhmann, N. (1995). Social systems. stanford university Press.

Luhmann, N. (2012). Theory of Society, vol. 1. Trans. Rhodes Barrett. Stanford: Stanford University Press.

Mauss, M. (1925). The gift, trans. I. Cunnison. London: Cohen and West.

Polanyi, K. (1944). The Great Transformation. NY: Farrar \& Rinehart.

Putnam, R. D. (1995). Tuning in, tuning out: The strange disappearance of social capital in America. PS: Political science \& politics, 28(4), 664-683.

Putnam, R. D. (2000). Bowling alone: America's declining social capital. In Culture and politics (pp. 223-234). Palgrave Macmillan, New York.

Putnam, R. D. (Ed.). (2004). Democracies in flux: The evolution of social capital in contemporary society. Oxford University Press, USA.

Seidl D and Whittington R (2014) Enlarging the strategy-as-practice research agenda: towards taller and flatter ontologies. Organization Studies 35(10): 1407-1421.

Stiglitz, E. J., Sen, A \& Fitoussi, J-E. Report by the Commission on the Measurement of Economic Performance and Social Progress.

Thurow, L. (1986). Zero-sum solution. Simon and Schuster.

Vaara E and Whittington R (2012) Strategy-as-practice: taking social practices seriously. Academy of Management Annals 6(1): 285-336. 
[1] https://www.visitsamsoe.dk/inspiration/energiakademiet/ 